УДК 616.3-008.6: 616.34-002

ОБЗОР

\title{
ЦЕЛИАКИЯ
}

'Жусупбекова Л.И., ${ }^{2}$ Абзулинова Д.Е., ${ }^{3}$ Ибраева А.К., 'Джаксалыкова К.К., ${ }^{1}$ Мухамеджанова А.А.

${ }^{1}$ НАО «Медииинский университет Aстана», Нур-Султан, e-mail: zhusly_06@mail.ru; ${ }^{2}$ Казахский национальный медицинский университет имени С.Д. Асфендиярова, Алматы,

${ }^{3}$ ГКП на ПХВ «Городская многопрофильная больница № 2» акимата, Нур-Султан

Целиакия, или глютеновая энтеропатия, рассматривается с позиции доказательной медицины как иммуноопосредованное заболевание тонкого кишечника вследствие воздействия глютена у генетически восприимчивых людей. Проблемы диагностики данного заболевания заключаются в разнообразии клинических проявлений - от гастроэнтерологических до внекишечных, а также возможности бессимптомного течения. Подтверждение диагноза целиакии у взрослых и детей должно основываться на клинических данных, результатах серологического исследования и биопсии двенадцатиперстной кишки на глютеновой диете. Особое внимание уделяется диагностике целиакии у людей с неклассической клинической картиной, с преобладанием внекишечных симптомов, а также с бессимптомной формой заболевания. Серологические исследования являются одним из важнейших компонентов выявления и диагностики целиакии, особенно определение IgA тканевой трансглутаминазы (TG2-IgA), общего IgA. Тщательный гистологический анализ биоптатов двенадцатиперстной кишки, подсчет лимфоцитов на HPF и морфометрия важны как для диагностики, так и для дифференциальной диагностики заболевания. В статье представлен обзор литературы, отражающий основные аспекты проблемы целиакии, включая эпидемиологию, этиопатогенез и клинику. С учетом современных рекомендаций изложены клинико-диагностические критерии и лечение целиакии у детей и взрослых.

Ключевые слова: целиакия, глютеновая энтеропатия, антиглиадиновые антитела, антитела к тканевой трансглутаминазе, клинические формы, лечение

\section{CELIAC DISEASE}

${ }^{1}$ Zhusupbekova L.I., ${ }^{2}$ Abzulinova D.E., ${ }^{3}$ Ibraeva A.K., ${ }^{1}$ Dzhaksalykova K.K., ${ }^{1}$ Mukhamedzhanova A.A.

${ }^{1}$ Astana Medical University, Nur-Sultan,e-mail: zhusly_06@mail.ru;

${ }^{2}$ Kazakh National Medical University named after S.D. Asfendiyarov, Almaty; ${ }^{3}$ City Multifunctional Hospital № 2 of akimat of Nur-Sultan

Celiac disease, or gluten enteropathy, is considered from the point of view of evidence-based medicine as an immuno-mediated disease of the small intestine due to gluten exposure in genetically susceptible people. The problems of diagnostics of this disease consist in variety of clinical manifestations - from gastroenterological to extraintestinal ones, and also possibility of asymptomatic form of disease. Confirmation of the diagnosis of celiac disease in adults and children should be based on clinical data, serological tests and a gluten diet biopsy of the duodenum. Special attention is paid to the diagnosis of celiac disease in people with a non-classical clinical picture with a predominance of extraintestinal symptoms, as well as with asymptomatic form of disease. Serological studies are one of the most important components in the detection and diagnosis of celiac disease, especially the determination of IgA tissue transglutaminase (TG2-IgA), total IgA. Thorough histological analysis of biopsy of the duodenum, lymphocyte counts on HPF and morphometry are important for both diagnosis and differential diagnosis of the disease. This article provides a literature review reflecting the main aspects of celiac disease, including epidemiology, etiopathogenesis and clinic. Clinical-diagnostic criteria and treatment of celiac disease in children and adults are outlined taking into account modern recommendations.

Keywords: celiac disease, gluten enteropathy, antigliadin antibodies, anti-tissue transglutaminase antibodies, clinical forms, treatment

Цель обзора - анализ современной литературы и обновленных рекомендаций по диагностике и лечению целиакии.

Целиакия в современной медицине рассматривается как аутоиммунная энтеропатия, возникающая вследствие приема глютена у лиц с генетической предрасположенностью [лейкоцитарный антиген человека (HLA) -DQ2 или -DQ8] [1], характеризующаяся наличием специфических антител [2]. В литературе можно встретить другие названия целиакии - нетропическая спру и глютеновая энтеропатия.

\section{История}

Жизненно важную роль в истории человечества сыграло потребление зерновых культур [3, с. 7110]. Уже в XV в. до н.э. были описаны кишечные заболевания с выраженным нарушением всасывания, по симптомам напоминающие целиакию [4]. Первое точное описание симптомов целиакии было дано Samuel Gee в 1888 г., который предположил, что соблюдение определенной диеты может значительно облегчить симптомы заболевания [5, с. 112]. В 1924 г. американ- 
ский педиатр Сидни Хаас опубликовал положительные результаты банановой диеты у детей с глютеновой энтеропатией - популярного лечения на протяжении нескольких десятилетий [6, с. 29]. В начале 1960-х гг. было установлено 3 важных аспекта: в основе возникновения целиакии лежит непереносимость глютена; в основе патогенеза - поражение слизистой оболочки тонкой кишки; и наконец, появление инструмента для проведения биопсии позволило ученым начать разгадывать тайны патогенеза глютеновой энтеропатии [7, с. 2].

\section{Эпидемиология}

До 1990-х гг. целиакия считалась редким заболеванием, которое в основном проявлялось у детей и распространение которого ограничивалось Западной Европой. В настоящее время целиакия является одной из основных проблем здравоохранения и поражает людей во всем мире [2, с. 1]. Согласно недавно проведенному метаанализу, распространенность целиакии, диагностированной на основании положительных результатов тестов на IgA анти-TG2 и/или антитела к эндомизию, составляет 1,4\% (доверительный интервал 95\%: 1,1-1,7\%). Распространенность целиакии, подтвержденной биопсией, составляет 0,7\% (ДИ 95\%: 0,5-0,9\%). В Африке и Северной Америке у 0,5\% населения диагностирована глютеновая энтеропатия, в Южной Америке у 0,4\% населения, в Азии целиакией страдает $0,6 \%$ населения и $0,8 \%$ в Европе и Океании [8, с. 3]. Самая высокая в мире частота распространения целиакии выявлена в специфических популяциях в Западной Сахаре $-5,6 \%$, что почти в десять раз выше, чем в большинстве европейских стран. В популяции также обнаружены одни из самых высоких частот носительства HLADQ2 и HLA-DQ8 и очень высокий уровень потребления глютена [9, с. 374]. Целиакия может возникнуть в любом возрасте и в различных клинических проявлениях [10], однако чаще встречается у детей $(0,9 \%$, у взрослых $0,5 \%)$ и у представителей женского пола $(0,6 \%$ против $0,4 \%$ мужского пола; $\mathrm{p}<0,001)$ [8, с. 5]. Риск возникновения целиакии значительно выше у родственников первой линии (5-10\%), у лиц с сахарным диабетом 1-го типа и другими аутоиммунными заболеваниями, с синдромом Дауна и рядом других сопутствующих патологий [11, с. 4].

Распространенность целиакии среди детей в Казахстане составляет 1:262, соотношение типичных форм к атипичным 1:5 [12]. В работе Т.К. Исабековой (2008) отмечена высокая распространенность целиакии среди детей г. Алматы. Проведенное скрининговое обследование 400 детей из группы риска выявило повышение титра антиглиадиновых антител в 21,5\% случаев [13]. Изучение распространенности, особенностей клинического течения и диагностики, а также вопросов лечения целиакии среди взрослых жителей Казахстана ранее не проводилось [14].

Подводя итог, можно сказать, что широкое распространение глютенсодержащих пищевых продуктов, генетическая предрасположенность и факторы риска, вероятно, обуславливают повсеместное и практически универсальное проявление этого заболевания.

\section{Этиология и патогенез}

Глютен - собирательное название различных белков злаков. Большинство белков, содержащихся в продуктах питания и отвечающих за иммунную реакцию при целиакии, являются проламинами. Проламины встречаются в таких зерновых культурах, как пшеница (глиадин), ячмень (ордеин), рожь (секалин), кукуруза (зеин) и овес (авенин). Высокое содержание глютамина в проламинах обеспечивает их устойчивость к желудочно-кишечным протеолитическим ферментам. Глютамин является отличным субстратом для дезамидирования тканевой трансглютаминазой [15, с. 6041]. Прием глютена генетически предрасположенными лицами с аллелями HLA типа II DQ2/DQ8 может вызвать Т-клеточноопосредованный иммунный ответ против тканевой трансглютаминазы, это в свою очередь, приводит к повреждению слизистой оболочки тонкого кишечника и в конечном счете к атрофии кишечных ворсинок [16, с. 7111$]$.

Как было указано выше, обязательным условием для развития целиакии является употребление глютена. Однако нет точного объяснения, почему не все генетически предрасположенные индивидуумы, потребляющие клейковину, заболевают глютеновой энтеропатией и почему болезнь может возникнуть позже, несмотря на многие десятилетия приема глютена [17, с. 224]. Действительно, многие авторы говорят о связи развития целиакии с питанием, инфекциями и использованием антибиотиков. Однако продолжительность грудного вскармливания и/или время введения глютена не влияют на риск развития целиакии [11, c. 4]. Несколько исследований показали, что дети, у которых впоследствии развилась целиакия, чаще страдали от гастроинтестинальных инфекций в более раннем возрасте [18-20]. Несмотря на это, остается необъяснимым, каким образом инфекции вызывают развитие глютеновой энтеро- 
патии. Существует также потенциальная связь между развитием целиакии и изменением состава микробиоты вследствие использования антибиотиков или родов путем кесарева сечения [21].

Несмотря на то, что факторы окружающей среды играют большую роль в развитии целиакии, отличительной чертой заболевания является его высокая наследственность и сильная ассоциация с носительством HLA, которая отражает центральную роль CD4+ Т-клеток [22]. Существует несколько типов специфических Т-клеток, распознающих пептид глютена [23]. В настоящее время идентифицировано три эпитопа глютена на Т-клетках: первый, эпитоп ограниченный глиадином, располагался на DQ2 (DQ2-I) [24], второй - на DQ8 (DQ8-I) [25] и третий эпитоп, ограниченный высокомолекулярным (HMW) глутенином, - на DQ8 (DQ8HMW-I) [26]. Генетическая гипотеза на сегодняшний день является одной из наиболее признанных Всемирной ассоциацией гастроэнтерологов [3].

\section{Клиника}

Клиническая картина целиакии широко варьирует, дебют заболевания может произойти в любом возрасте: первый пик манифестации - в первые 2 года жизни, вскоре после прекращения грудного вскармливания и введения глютенсодержащих продуктов, второй пик - во второе или третье десятилетие жизни [27].

За последние 10 лет предпринимались попытки прийти к консенсусу в терминологии клинических стадий целиакии. Так, в журнале Lancet были опубликованы основные формы клинического проявления заболевания:

- потенциальная: положительные серологические тесты на фоне отсутствия симптомов и нормальной биопсии кишечника. Термин «потенциал» также используется у лиц, которые никогда не имели диагноза целиакии, но имеют соответствующий генетический фон (HLA-DQ2/DQ8);

- асимптоматическая: отсутствие симптомов на фоне положительных серологических тестов и соответствующей гистологической картины;

- симптоматическая: наличие как кишечных, так и внекишечных симптомов;

-классическая: наличие симптомов мальабсорбции: диарея, стеаторея, потеря веса, задержка в развитии, наличие/отсутствие анемии;

- неклассическая: кишечная (боли в животе, метеоризм, запоры) или внекишечная (дефицит железа, хроническая усталость, головная боль, остеопения/остеопороз, неврологические расстройства) манифестация заболевания;

-рефрактерная: наличие симптомов глютеновой энтеропатии и атрофии кишечных ворсинок, которые сохраняются в течение 1 года после соблюдения строгой безглютеновой диеты [28, 29].

У некоторых детей также могут проявляться признаки эмоционального расстройства, «изменения настроения» и вялости [1]. Целиакия часто ассоциируется с другими заболеваниями, связанными с комплексом гистосовместимости, которые опосредуются иммунологическими механизмами: герпетиформным дерматитом, язвами полости рта, IgA-нефропатией, ревматоидным артритом, саркоидозом [21].

\section{Диагностика}

Диагностика целиакии представляет собой сложный процесс, так как симптомы заболевания могут значительно варьировать от пациента к пациенту [13], а случаи поздней диагностики встречаются по сей день [30].

Подтверждение диагноза целиакии у взрослых и детей должно основываться на клинических данных, данных серологического исследования и биопсии двенадцатиперстной кишки. Особый интерес и важность представляет диагностика целиакии у взрослых и детей с неклассической клинической картиной, с преобладанием внекишечных симптомов, а также с бессимптомной формой заболевания.

Европейское общество по изучению целиакии (ESsCD) рекомендует проводить диагностику заболевания следующим группам пациентов (высокий уровень доказательности):

1) взрослые с клиническими и лабораторными признаками мальабсорбции;

2) лица, у первой линии родственников которых имеется подтвержденный диагноз целиакии;

3) пациенты с необъясненными повышениями трансаминаз в крови;

4) лица с сахарным диабетом 1 типа [11, c. 589].

Диагноз целиакии ставится путем первичного серологического исследования и подтверждается гистопатологическим исследованием биоптатов двенадцатиперстной кишки [31]. Серологические исследования являются одним из важнейших компонентов выявления и диагностики целиакии, особенно определение IgA тканевой трансглутаминазы (TG2-IgA), общего $\operatorname{IgA.~Тщательный~гистологический~анализ~}$ биоптатов двенадцатиперстной кишки, под- 
счет лимфоцитов на HРF и морфометрия важны как для диагностики, так и для дифференциальной диагностики [32].

Из-за высокого риска развития негативных последствий для здоровья в будущем важно диагностировать целиакию не только у детей с очевидными кишечными симптомами, но и у тех, кто имеет менее выраженную клиническую картину, только внекишечные проявления или асимптомное течение болезни.

Согласно руководству ESsCD диагностике подлежат следующие группы детей:

1. Дети с необъяснимыми симптомами хронической диареи или запорами, задержкой в развитии, потерей веса, задержкой полового созревания, аменореей, железодефицитной анемией, тошнотой или рвотой, хроническими болями в животе, судорогами, хронической усталостью, рецидивирующим афтозным стоматитом, сыпью, похожей на герпетиформный дерматит, переломами костей и аномальной биохимией печени.

2. Дети, у которых отсутствуют симптомы, но имеется повышенный риск развития глютеновой энтеропатии: сахарный диабет 1 типа, синдром Дауна, аутоиммунный тиреоидит, синдром Тёрнера, синдром Вильямса, селективный дефицит IgA, аутоиммунная болезнь печени и наличие родственников первой линии, имеющих целиакию [11, с. 605].

Европейское общество детской гастроэнтерологии, гепатологии и питания (ESPGHAN) в качестве начального скрининга рекомендует всем детям с подозрением на целиакию проводить тестирование на общий IgA и TGA-IgA. У пациентов c низкими суммарными концентрациями $\operatorname{IgA~в~качестве~второго~шага~следует~про-~}$ вести тест на IgG (DGP, EMA или TGA). Тестирование на антитела EMA, DGP или AGA (IgG и IgA) в качестве первичного скрининга в клинической практике не рекомендуется [33].

На основе клинических исследований $[34,35]$ ESPGHAN рекомендует у бессимптомных детей проводить диагностику целиакии без биопсии двенадцатиперстной кишки. Диагностика целиакии без биопсии безопасна у детей с высокими значениями TGA-IgA ( $\geq 10$ раз больше верхнего предела нормы) с соответствующими тестами и положительными эндомизиальными антителами (EMA-IgA) в сыворотке крови. Однако детям с положительным значением TGA-IgA, но с низким титром (<10-кратным верхним пределом нормы) рекомендуют проводить биопсию для снижения риска ложноположительного диагноза.
HLA-тестирование и наличие симптомов не являются обязательными критериями для серологической диагностики без биопсии [33, с. 5].

\section{Лечение}

До настоящего времени единственным эффективным методом лечения целиакии является безглютеновая диета. Считается, что строгое и пожизненное соблюдение данной диеты вызывает ремиссию у пациентов с целиакией и приводит к частичному или полному заживлению слизистой оболочки двенадцатиперстной кишки [36, 37]. Также существуют некоторые свидетельства того, что безглютеновая диета может даже снизить риск злокачественных новообразований у этих пациентов [38]. Однако эти преимущества сопровождаются некоторыми недостатками, включая негативное воздействие на качество жизни, психологические проблемы, страх перед непроизвольным/необратимым потреблением глютена (как показано в многоцентровых исследованиях GIP) [39], возможную нехватку витаминов и минералов, метаболический синдром, повышенный риск сердечно-сосудистых заболеваний и часто сильные запоры. Все это можно преодолеть с помощью инструктирования пациента о рисках неконтролируемого безглютенового режима, предоставления рекомендаций по питанию диетологом с опытом работы в области целиакии, а также с помощью поддержки психолога [40, с. 15].

Помимо модификации диеты, ряд текущих клинических исследований показал многообещающие результаты в области лечения целиакии, однако они требуют дальнейшего изучения:

1) протестированы добавки орального фермента, расщепляющего глютен: Латиглутиназа (IMGX-003 или ALV-003), ANPEP (пролиловые эндопептидазы, получаемые из Aspergillus niger) и STAN1 (коктейль микробных ферментов);

2) всасывание глютена может быть предотвращено путем перекрытия плотных соединений с помощью ларазотида ацетата;

3) начато исследование по TG2ингибированию и модуляции иммунной системы, а также по блокированию HLA-DQ2;

4) установлена индукция толерантности к глютену с помощью Nexvax2 - новой, пептидной, эпитопной иммунотерапии, основанной на принципе десенсибилизирующей терапии при аллергических состояниях [11, с. 612].

Особый интерес представляет лечение рефрактерной формы целиакии. Согласно ретроспективному исследованию, прием будесонида обеспечивает клиническую ре- 
миссию и восстановление ворсинок примерно в 90\% обоих типов рефрактерной целиакии [41, с. 8$]$.

\section{Заключение}

На сегодняшний день существует по меньшей мере две причины широкого распространения глютеновой энтеропатии: повсеместное увеличение числа аутоиммунных заболеваний и улучшение методов диагностики целиакии. Однако широкий спектр симптомов заболевания, а также наличие рефрактерных форм целиакии, трудно поддающихся терапии, затрудняют своевременную диагностику и лечение. Как следствие, многие случаи остаются недиагностированными в течение длительного времени. В настоящее время не хватает стандартизированных, основанных на доказательных данных рекомендаций в отношении детей. Учитывая вышеперечисленное, существует постоянный интерес к новым методам диагностики и лечения глютеновой энтеропатии.

\section{Список литературы}

1. Scherf K.A., Catassi C., Chirdo F., Ciclitira P.J., Feighery C., Gianfrani C., Koning F., Lundin K.E.A., Schuppan D., Smulders M.J.M., Tranquet O., Troncone R., Koehler P. Recent Progress and Recommendations on Celiac Disease From the Working Group on Prolamin Analysis and Toxicity. Frontiers in Nutrition. 2020. Vol. 7. No. 29. P. 1-14. DOI: 10.3389 fnut.2020.00029.

2. Lindfors K., Ciacci C., Kurppa K., Lundin K.E.A., Makharia G.K., Mearin M.L., Murray J.A., Verdu E.F., Kaukinen K. Coeliac Disease. Nature Reviews Disease Primers. 2019. Vol. 5. No. 1. P. 3. DOI: 10.1038/s41572-018-0054-z.

3. Caio G., Volta U., Sapone A., Leffler D.A., De Giorgio R., Catassi C., Fasano A. Celiac disease: a comprehensive current review. BMC Medicine. 2019. Vol. 17. No. 1. P. 142. DOI: 10.1186/s12916-019-1380-z.

4. Bureš J. History of celiac disease. Vnitrni lekarstvi 2018. Vol. 64. No. 6. P. 600-601.

5. Losowsky M.S. A History of Coeliac Disease. Digestive Diseases. 2008. Vol. 26. No. 2. P. 112-120. DOI: 10.1159/000116768.

6. Freeman H.J. Celiac Disease: A Disorder Emerging from Antiquity, Its Evolving Classification and Risk, and Potential New Treatment Paradigms. Gut and Liver. 2015. Vol. 9. No. 1. P. 28-37. DOI: $10.5009 /$ gnl14288.

7. Guandalini S. A Brief History of Celiac Disease. A publication of the university of Chicago celiac disease center. 2007. Vol. 7. No. 3. P. $1-2$.

8. Singh P., Arora A., Strand T.A., Leffler D.A., Catassi C., Green P.H., Kelly C.P., Ahuja V., Makharia G.K. Global prevalence of celiac disease: systematic review and meta-analysis. Clinical Gastroenterology and Hepatology. 2017. Vol. 16. No. 6. P. 823-836. DOI: 10.1016/j.cgh.2017.06.037.

9. Lionetti E., Gatti S., Pulvirenti A., Catassi C. Celiac disease from a global perspective. Best Practice and Research Clinical Gastroenterology. 2015. Vol. 29. No. 3. P. 365-379. DOI: 10.1016/j.bpg.2015.05.004

10. Fasano A., Berti I., Gerarduzzi T., Not T., Colletti R.B., Drago S., Elitsur Y., Green P.H.R., Guandalini S., Hill I.D., Pietzak M., Ventura A., Thorpe M., Kryszak D., Fornaroli F., Wasserman S.S., Murray J.A., Horvath K. Prevalence of celiac disease in at-risk and not-at-risk groups in the United States: a large multicenter study. Arch Intern Med. 2003. Vol. 163. No. 3. P. 286-292.

11. Al-Toma A., Volta U., Auricchio R., Castillejo G., Sanders D.S., Cellier C., Lundin K.E.A. European Society for the Study of Coeliac Disease (ESsCD) guideline for coeliac disease and other gluten-related disorders. United European Gastroenterology Journal. 2019. Vol. 7. No. 5. P. 583-613. DOI: $10.1177 / 2050640619844125$.

12. Шарипова М.Н. Клинико-эпидемиологические и генетические особенности целиакии у детей Казахстана // Педиатрия. 2009. Т. 87. № 1. С. 106-108.

13. Исабекова Т.К. Клинико-эпидемиологические особенности и организация лечения целиакии у детей. Автореф. дисс. ... канд. мед. наук. Алматы, 2008. 23 с.

14. Искаков Б.С., Капасова А.Т. Клинико-лабораторные аспекты диагностики целиакии у взрослых (обзор литературы) // Medicine (Almaty). 2017. № 9. C. 46-52.

15. Gujral N., Freeman H.J., Thomson A.B. Celiac disease: prevalence, diagnosis, pathogenesis and treatment. World Journal Gastroenterology. 2012. November 14. Vol. 18. No. 42. P. 6036-6059. DOI: 10.3748/wjg.v18.i42.6036.

16. Elli L., Branchi F., Tomba C., Villalta D., Norsa L., Ferretti F., Roncoroni L., Bardella M.T. Diagnosis of Gluten Related Disorders: Celiac Disease, Wheat Allergy and Non-Celiac Gluten Sensitivity. World Journal of Gastroenterology. 2015. Vol. 21. No. 23. P. 7110-7119. DOI: 10.3748/wjg.v21.i23.7110.

17. Kondrashova A., Mustalahti K., Kaukinen K., Viskari H., Volodicheva V., Haapala A.-M., Ilonen J., Knip M., Mäki M., Hyöty H., Epivir Study Group. Lower economic status and inferior hygienic environment may protect against celiac disease. Annals of Medicine. 2008. Vol. 40. No. 3. P. 223-231. DOI: $10.1080 / 07853890701678689$.

18. Marild K., Kahrs C.R., Tapia G., Stene L.C., Stordal K. Infections and risk of celiac disease in childhood: a prospective nationwide cohort study. The American Journal of Gastroenterology. 2015. Vol. 110. No. 10. P. 1475-1484. DOI: 10.1038/ ajg.20 15.287.

19. Myléus A., Hernell O., Gothefors L., Hammarström M.-L., Persson L.-A., Stenlund H., Ivarsson A. Early infections are associated with increased risk for celiac disease: an incident case-referent study. BMC Pediatrics. 2012. Vol. 12. P. 194-212. DOI: $10.1186 / 1471-2431-12-194$.

20. Canova C., Zabeo V., Pitter G., Romor P., Baldovin T., Zanotti R., Simonato L. Association of Maternal Education, Early Infections, and Antibiotic Use With Celiac Disease: A Population-Based Birth Cohort Study in Northeastern Italy. 2014. American Journal of Epidemiology. 2014. Vol. 180. No. 1. P. 76-85. DOI: 10.1093/aje/kwu101.

21. Tye-Din J.A., Galipeau H.J., Agardh D. Celiac Disease: A Review of Current Concepts in Pathogenesis, Prevention, and Novel Therapies. Frontiers in Pediatrics. 2018. Vol. 6. P. 350369. DOI: $10.3389 /$ fped.2018.00350.

22. Kuja-Halkola R., Lebwohl B., Halfvarson J., Wijmenga C., Magnusson P.K.E., Ludvigsson J.F. Heritability of nonHLA genetics in coeliac disease: a population-based study in 107000 twins. Gut. 2016. Vol. 65. No. 11. P. 1793-1798. DOI: 10.1136/gutjnl-2016-311713.

23. Lundin K.E., Sollid L.M., Anthonsen D., Norén O., Molberg O., Thorsby E., Sjöström H. Heterogenous reactivity patterns of HLA-DQ-restricted small intestinal T-cell clones from patients with celiac disease. Gastroenterology. 1997. Vol. 112. No. 3. P. 752-759. doi:10.1053/gast.1997.v112.pm9041236.

24. Sjöström H., Lundin K.E., Molberg O., Körner R., McAdam S.N., Anthonsen D., Quarsten H., Norén O., Roepstorff P., Thorsby E., Sollid L.M. Identification of a gliadin Tcell epitope in coeliac disease: general importance of gliadin deamidation for intestinal T-cell recognition. Scandinavian Journal of Immunology. 1998. Vol. 48. No. 2. P. 111-115. DOI: 10.1046/j.1365-3083.1998.00397.x.

25. Van de Wal Y., Kooy Y.M.C., van Veelen P.A., Pena S.A., Mearin L.M., Molberg O., Koning F. Small intesti- 
nal $\mathrm{T}$ cells of celiac disease patients recognize a natural pepsin fragment of gliadin. Proceedings of the National Academy of Sciences. 1998. Vol. 95. No. 17. P. 10050-10054. DOI: 10.1073/ pnas.95.17.10050.

26. Van de Wal Y., Kooy Y.M.C., van Veelen P., Vader W., August S.A., Drijfhout J.W., Peña S.A., Koning F. Glutenin is involved in the gluten-driven mucosal T cell response. European Journal of Immunology. 1999. Vol. 29. No. 10. P. 3133-3139. DOI: 10.1002 (sici)1521-4141(199910)29:10<3133::aid-immu3133>3.0.co;2-g.

27. Fasano A. Celiac Disease - How to Handle a Clinical Chameleon. New England Journal of Medicine. 2003. Vol. 348. No. 25. P. 2568-2570. DOI: 10.1056/nejme030050.

28. Lebwohl B., Sanders D.S., Green P.H.R. Coeliac disease. Lancet. 2018. Vol. 391. No. 10115. P. 70-81. DOI: 10.1016/s0140-6736(17)31796-8

29. Itzlinger A., Branchi F., Elli L., Schumann M. GlutenFree Diet in Celiac Disease Forever and for All? Nutrients. 2018 Vol. 10. No. 11. P. 1796-1810. DOI: 10.3390/nu10111796.

30. Жусупбекова Л.И., Ибраева А.К., Джаксалыкова К.К., Нуркина Д.А., Аманжолова Ж.А., Кубайдуллина А.К. Случай из практики: поздняя диагностика целиакии // Научное обозрение. Медицинские науки. 2020. № 4. C. 23-27. DOI 10.17513/srms.1123.

31. Di Niro R., Snir O., Kaukinen K., Yaari G., Lundin K.E.A., Gupta N.T., Sollid L.M. Responsive population dynamics and wide seeding into the duodenal lamina propria of transglutaminase-2-specific plasma cells in celiac disease. Mucosal Immunology. 2015. Vol. 9. No. 1. P. 254-264. DOI: 10.1038/mi.2015.57.

32. Iversen R., Fleur du Pre M., Di Niro R., Sollid L.M Igs as Substrates for Transglutaminase 2: Implications for Autoantibody Production in Celiac Disease. The Journal of Immunology. 2015. Vol. 195. No. 11. P. 5159-5168. DOI: 10.4049 / jimmunol.1501363.

33. Husby S., Koletzko S., Korponay-Szabó I., Kurppa K., Mearin M. L., Ribes-Koninckx C., Wessels M. European Society Paediatric Gastroenterology, Hepatology and Nutrition Guidelines for Diagnosing Coeliac Disease 2020. Journal of Pediatric Gastroenterology and Nutrition. 2020. Vol. 70. No. 1. P. 141 156. DOI: $10.1097 / \mathrm{mpg} .0000000000002497$
34. Werkstetter K.J., Korponay-Szabó I.R., Popp A., Villanacci V., Salemme M., Heilig G., Lillevang S.T., Mearin M.L., Ribes-Koninckx C., Thomas A., Troncone R., Filipiak B., Mäki M., Gyimesi J., Najafi M., Dolinšek J., Sander S.D., Auricchio R., Sadat A.T.E., Werkstetter K.J., Korponay-Szabo I.R., Popp A. Accuracy in Diagnosis of Celiac Disease Without Biopsies in Clinical Practice. Gastroenterology. 2017. Vol. 153. No. 4. P. 924-935.

35. Wolf J., Petroff D., Richter T., Auth M.K.H., Uhlig H.H., Laass M.W., Lauenstein P., Krahl A., Händel N., Jan de Laffolie, Hauer A.C., Kehler T., Flemming G., Schmidt F., Rodrigues A., Hasenclever D., Mothes T. Validation of Antibody-Based Strategies for Diagnosis of Pediatric Celiac Disease Without Biopsy. Gastroenterology. 2017. Vol. 153. No. 2. P. 410-419. DOI: 10.1053/j.gastro.2017.04.023.

36. Ludvigsson J.F., Bai J.C., Biagi F., Card T.R., Ciacci C., Ciclitira P.J. Diagnosis and management of adult coeliac disease: guidelines from the British Society of Gastroenterology. Gut. 2014. Vol. 63. No. 8. P. 1210-1228. DOI: 10.1136/ gutjnl-2013-306578.

37. Itzlinger A., Branchi F., Elli L., Schumann M. GlutenFree Diet in Celiac Disease Forever and for All? Nutrients. 2018. Vol. 10. No. 11. P. 1796. DOI: 10.3390/nu10111796.

38. De Re V., Magris R., Cannizzaro R. New Insights into the Pathogenesis of Celiac Disease. Frontiers in Medicine. 2017. Vol. 4. P. 137. DOI: 10.3389/fmed.2017.00137.

39. Moreno M.L., Cebolla Á., Muñoz-Suano A., CarrilloCarrion C., Comino I., Pizarro Á., León F., Rodríguez-Herrera A., Sousa C. Detection of gluten immunogenic peptides in the urine of patients with coeliac disease reveals transgressions in the gluten-free diet and incomplete mucosal healing. Gut. 2017. Vol. 66. No. 2. P. 250-257. DOI: 10.1136/gutjnl-2015-310148.

40. Caio G., Volta U., Sapone A., Leffler D.A., De Giorgio R., Catassi C., Fasano A. Celiac disease: a comprehensive current review. BMC Medicine. 2019. Vol. 17. No. 1. P. 142162. DOI: 10.1186/s12916-019-1380-z.

41. Mukewar S.S., Sharma A., Rubio-Tapia A., Wu T.-T., Jabri B., Murray J.A. Open-Capsule Budesonide for Refractory Celiac Disease. The American Journal of Gastroenterology. 2017. Vol. 112. No. 6. P. 959-967. DOI: 10.1038/ajg.2017.71. 